Research Paper

\title{
Microbial lipids and added value metabolites production by Yarrowia lipolytica from pork lard
}

\author{
Marlene Lopes, Andreia S. Gomes, Carla M. Silva, Isabel Belo* \\ CEB - Centre of Biological Engineering, University of Minho, Campus de Gualtar, 4710-057 Braga, Portugal
}

\section{A R T I C L E I N F O}

\section{Keywords:}

Yarrowia lipolytica

Biorefinery

Pork lard

Microbial lipids

Lipase

Citric acid

\begin{abstract}
A B S T R A C T
Yarrowia lipolytica is a suitable microbial platform to convert low-value hydrophobic substrates into microbial oils and other important metabolites. In this work, this yeast species was used to simultaneously synthetize ex novo lipids and produce citric acid and lipase from animal fat (pork lard) adding higher value to the low-cost fatty substrate. The effect of $\mathrm{pH}$, lard concentration, arabic gum concentration and oxygen mass transfer rate (OTR) on lipids accumulation on Y. lipolytica batch cultures was assessed by an experimental design based on Taguchi method. OTR was by far the most influential parameter in the range of $96 \mathrm{mg} \mathrm{L}^{-1} \mathrm{~h}^{-1}-480 \mathrm{mg} \mathrm{L}^{-1} \mathrm{~h}^{-1}$.

A bio-modification of initial lipidic substrate was observed and, depending on the nutritional and operational conditions, specialty lipids with specific composition and high added-value were obtained. The unsaturated-tosaturated fatty acids ratio of these microbial lipids is higher than in initial substrate, which indicates that they are more suitable than animal fat for food additives. Moreover, the simultaneous induction of lipase and citric acid by $Y$. lipolytica growing in animal fat demonstrates that a biorefinery approach may be designed based on animal fat raw material.
\end{abstract}

\section{Introduction}

Oils derived from microorganisms, which are often referred to as microbial oils, microbial lipids or single cell oils (SCO) can be interesting as a potential source to food supplements, since some microorganisms are able to produce polyunsaturated fatty acids, such as those belonging to the omega- 3 and omega- 6 series (Béligon et al., 2016; Bellou et al., 2016a).

Lipid-accumulating microorganisms, also called oleaginous microorganisms, have the capacity to accumulate lipid content higher than $20 \%$ of their dry weight. Several microbial genera, especially molds (Mucor mucedo, Emerisella nidulans, Aspergillus sp.) and yeasts (Rhodotorula sp, Geotrichum sp., Yarrowia lipolytica), are known to be high lipid producer under specific culture conditions (Aggelis et al., 1997; Kinoshita and Ota, 2001; Roux-Van der Merwe et al., 2005; Papanikolaou et al., 2011; Thevenieau and Nicaud, 2013; Donot et al., 2014). In lipid production by oleaginous microorganisms, two distinct metabolic pathways are involved: ex novo lipid accumulation (from hydrophobic substrates) and de novo lipid synthesis (from hydrophilic substrates). In contrast to de novo lipid synthesis, ex novo lipid production is a primary anabolic process, occurring simultaneously with cell growth. In fact, ex novo lipid synthesis is the bio-modification of oils and fats by oleaginous microorganisms and the fatty acid composition of the fat used as substrate greatly influences the process of lipid production (Donot et al., 2014; Papanikolaou and Aggelis, 2011).

The non-conventional yeast $Y$. lipolytica has the ability to assimilate fatty substances (Tsigie et al., 2011; Cheirsilp and Louhasakul, 2013; Abghari and Chen, 2014), having a great lipid accumulation capacity with most of the storage lipids produced in the form of triacylglycerols (TAG) (Thevenieau and Nicaud, 2013; Abghari and Chen, 2014). Y. lipolytica has been used as a model microorganism for the ex novo lipid accumulation, since it can "upgrade" the composition of fatty materials utilized as substrates with concomitant production of tailor-made lipids of high added value. One example of these specialty lipids is cocoabutter substitute, produced by wild strains of $Y$. lipolytica from industrial derivative fat (Papanikolaou et al., 2001) or mutton fat (Xiong et al., 2015). Moreover, engineered strains capable of producing polyunsaturated fatty acids for human nutrition with health benefits, such as eicosapentanoic acid (Xue et al., 2013) and conjugated linoleic acids (Zhang et al., 2013) were constructed.

Difficulties of industrial microbial lipids production are related to the high cost of fermentation and oil extraction from cells and a critical factor for the final cost of microbial lipids is the quantity of oil accumulated per unit of dry cellular mass. In this regard, the use of reliable

\footnotetext{
* Corresponding author.

E-mail address: ibelo@deb.uminho.pt (I. Belo).
} 
and low-cost raw materials as substrate for microbial lipids production can decrease the total cost of the process. Slaughterhouses and meat processing industry are very important and abundant in Portugal (more than 220 in all country), producing large quantity of wastes, most of them lipid-reach wastes that are an environmental burden. Due to their composition, these residues are suitable for microbial lipids production (Béligon et al., 2016), in particular by Y. lipolytica strains, which have specific metabolic pathways to assimilate efficiently fatty substances (Fickers et al., 2005).

Although several agro-industrial wastes, such as palm oil mill effluent, crude glycerol (Cheirsilp and Louhasakul, 2013) or even an industrial derivate of animal fat (stearin) (Papanikolaou et al., 2003) have been used for microbial lipids production by $Y$. lipolytica, in our best knowledge this is the first report about the use of pork lard to this purpose. Nowadays lard is not used as much in food preparation, since it is associated to a potential cause of vascular and heart disease (Yamsub et al., 2014), and therefore the price of animal fat (250-375 US\$/ton) is relatively low (Banković-Ilić et al., 2014), which makes it a cheap and promising substrate for microbial oils production.

Thus, our aim was to evaluate the ability of a wild type $Y$. lipolytica strain to assimilate lard as sole carbon source and produce microbial oils and other added value products (lipase and citric acid) in order to assess the potential utilization of $Y$. lipolytica as a biorefinery platform. The effect of selected parameters ( $\mathrm{pH}$, lard concentration, arabic gum concentration and oxygen mass transfer rate) on microbial lipids, lipase and citric acid production by $Y$. lipolytica W29 was assessed by a fractional factorial design based on Taguchi method. It is worth to notice that the simultaneous effect of these four factors has never been studied before.

\section{Materials and methods}

\subsection{Yeast strain}

Yarrowia lipolytica W29 (ATCC 20460) was maintained on yeast extract peptone dextrose agar medium (YPDA) at $4{ }^{\circ} \mathrm{C}$ to a maximum of two weeks. The YPDA medium had the following composition: peptone $20 \mathrm{~g} \mathrm{~L}^{-1}$, glucose $20 \mathrm{~g} \mathrm{~L}^{-1}$, yeast extract $10 \mathrm{~g} \mathrm{~L}^{-1}$ and agar $20 \mathrm{~g} \mathrm{~L}^{-1}$.

\subsection{Lard characterization}

Each $100 \mathrm{~g}$ of the commercial pork lard used contains: $891 \mathrm{kcal},<0.1 \mathrm{~g}$ of salt and $99 \mathrm{~g}$ of lipids, composed by (w/w) stearic acid $13.3 \%$, palmitic acid $27.8 \%$, linoleic acid $19.1 \%$ and oleic acid $39.5 \%$.

\subsection{Experimental design - effect of $p H$, lard concentration, arabic gum concentration and OTR}

Lard utilization by Y. lipolytica W29 was studied using the Taguchi method, a fractional factorial experimental design that uses orthogonal arrays for the optimization of different factors. In this study, Taguchi design was used to achieve the highest production by optimizing the medium composition and operational conditions.

The experimental design was done using a L9 orthogonal array using Qualitek-4 software (Nutek, Bloomfield Hills, USA). Four factors $(\mathrm{pH}$, lard concentration, arabic gum concentration and oxygen transfer rate, OTR) were combined and varied in three levels $\left(4^{3}\right)$. From the Qualitek-4 software (Nutek, Bloomfield Hills, USA), a total of nine experiments were designed (Table 1 ).

The experiments were performed in $500 \mathrm{~mL}$ Erlenmeyer flasks filled with $200 \mathrm{~mL}$ of production medium. Yeast cells were pre-grown overnight in YPD medium (glucose $20 \mathrm{~g} \mathrm{~L}^{-1}$, peptone $20 \mathrm{~g} \mathrm{~L}^{-1}$, yeast extract $\left.10 \mathrm{~g} \mathrm{~L}^{-1}\right)$, centrifuged and resuspended $\left(0.5 \mathrm{~g} \mathrm{~L}^{-1}\right.$ of initial cellular density) in production medium (lard, yeast extract $0.5 \mathrm{~g} \mathrm{~L}^{-1}$ and arabic gum dissolved in potassium phosphate buffer $0.1 \mathrm{M}$ ). The
Table 1

L9 orthogonal array of Taguchi design: parameters and levels used in the experimental design for each run in batch cultures of Y. lipolytica W29.

\begin{tabular}{|c|c|c|c|c|c|c|}
\hline Run & \multicolumn{3}{|c|}{$\mathrm{pH}$} & \multicolumn{2}{|l|}{ [lard] } & OTR \\
\hline 1 & & 1 & & 1 & 1 & 1 \\
\hline 2 & & 1 & & 2 & 2 & 2 \\
\hline 3 & & 1 & & 3 & 3 & 3 \\
\hline 4 & & 2 & & 1 & 2 & 3 \\
\hline 5 & & 2 & & 2 & 3 & 1 \\
\hline 6 & & 2 & & 3 & 1 & 2 \\
\hline 7 & & 3 & & 1 & 3 & 2 \\
\hline 8 & & 3 & & 2 & 1 & 3 \\
\hline 9 & & 3 & & 3 & 2 & 1 \\
\hline Levels & $\mathrm{pH}$ & & [lard] $/ \mathrm{g} \mathrm{L}^{-1}$ & & [arabic gum]/g L ${ }^{-1}$ & $\mathrm{OTR} / \mathrm{mg} \mathrm{L}^{-1} \mathrm{~h}^{-1}$ \\
\hline 1 & 5.6 & & 20 & & 5 & 96 \\
\hline 2 & 6.5 & & 50 & & 10 & 480 \\
\hline 3 & 7.2 & & 80 & & 20 & 192 \\
\hline
\end{tabular}

experiments were carried out at different OTR values (in $\mathrm{mg} \mathrm{L}^{-1} \mathrm{~h}^{-1}$ ): 96, 192 and 480 achieved at $170 \mathrm{rpm}$ using Erlenmeyer flasks without baffles, $220 \mathrm{rpm}$ using Erlenmeyer flasks without baffles and at 170 rpm using Erlenmeyer flasks with baffles, respectively. OTR was estimated in blank assays by the sulfite oxidation method as described by Lopes et al. (2013).

The responses analyzed were microbial lipids content (expressed as the ratio of lipids mass and dry cellular mass, \%), lipase activity $\left(\mathrm{U} \mathrm{L}^{-1}\right)$ and citric acid concentration $\left(\mathrm{g} \mathrm{L}^{-1}\right)$. Data obtained in the experimental design was processed in the Qualitek-4 software applying "bigger is better" quality characteristics to evaluate the optimal culture conditions for the maximization of microbial lipids, lipase and citric acid. Statistical analysis was done by one-way analysis of variance (ANOVA).

\subsection{Bioreactor experiments}

Batch cultivations in a 2-L bioreactor (BIOLAB, B. Braun, Germany) were performed with 1.4-L of production medium (lard $50 \mathrm{~g} \mathrm{~L}^{-1}$, yeast extract $0.5 \mathrm{~g} \mathrm{~L}^{-1}$ and arabic gum $5 \mathrm{~g} \mathrm{~L}^{-1}$ dissolved in potassium phosphate buffer $0.1 \mathrm{M}, \mathrm{pH} 5.6$ ) at $27^{\circ} \mathrm{C}$. Yeast cells were pre-grown overnight in $500 \mathrm{~mL}$ Erlenmeyer flasks with $200 \mathrm{~mL}$ of YPD medium at $27^{\circ} \mathrm{C}$ and $170 \mathrm{rpm}$, centrifuged and resuspended in production medium ( $0.5 \mathrm{~g} \mathrm{~L}^{-1}$ of initial cellular density). In order to validate the effect of OTR on microbial lipids production, experiments were performed varying simultaneously the stirring speed and the specific air flow rate, obtaining values of OTR equal to $122 \mathrm{mg} \mathrm{L}^{-1} \mathrm{~h}^{-1}$ (200 rpm, $1 \mathrm{vvm}$ ) and $605 \mathrm{mg} \mathrm{L}^{-1} \mathrm{~h}^{-1}$ (400 rpm, $2 \mathrm{vvm}$ ).

Dissolved oxygen tension during cell cultivation was measured with a polarographic membrane probe (Inpro 6820/12/320, Metler Toledo, USA) and the respective meter (Type 170, Metler Toledo, USA).

\subsection{Analytical methods}

Yeast cells were observed in an Olympus BX51 microscope immediately after sampling ( $120 \mathrm{~h}$ of growth) for the intracellular lipids visualization. Cellular density was assessed by cell counting in the microscope and converted to dry cell mass per liter by a calibration curve.

Quantitative measurement of microbial lipids was performed with phospho-vanillin colorimetric method, after extraction with methanol and chloroform (1:1, v/v) from lyophilized cells. Prior to quantification method, the yeast cells were separated from the culture medium by centrifugation, washed twice with PBS buffer and hexane (in order to remove the eventual lard adhered to the cells) and lyophilized. Lyophilized cells (no fat on powder surface was observed, which means that no lard was adhered to the dry cells) were crushed for cell 
disruption and microbial lipids were then extracted with methanol and chloroform. The phospho-vanillin (vanillin dissolved in ortophosphoric acid $85 \%$ ) reacts with lipids to produce a pink color and its intensity was quantified by measuring absorbance at $490 \mathrm{~nm}$ in a microplate reader (TECAN Sunrise, Switzerland). The absorbance was converted to lipids concentration $\left(\mathrm{g} \mathrm{L}^{-1}\right)$ by a calibration curve (olive oil was used as standard).

The quantification of microbial lipids (accumulated intracellularly) was carried out after centrifugation, washing and lyophilization of Y. lipolytica cells. The yeast cells were: separated from the culture medium by centrifugation, washed twice with PBS buffer and hexane (in order to remove the eventual lard adhered to the cells) and lyophilized. Lyophilized cells (no fat on powder surface was observed, which means that no lard was adhered to the dry cells) were crushed for cell disruption and microbial lipids were extracted with methanol and chloroform $(1: 1, \mathrm{v} / \mathrm{v})$.

Microbial lipids were transformed into their corresponding methyl esters with methanol acidified with $\mathrm{H}_{2} \mathrm{SO}_{4} 10 \%$ (v/v), followed by extraction with $n$-hexane $(1: 2, \mathrm{v} / \mathrm{v})$. The organic phase containing fatty acid methyl esters (FAME) was analyzed by gas chromatography in a CP-3800 gas chromatograph (Varian Inc., USA) fitted with FID detector and Bruker BRU-MS nonpolar column (15 m length, $0.25 \mathrm{~mm}$ internal diameter, $0.25 \mu \mathrm{m}$ film thickness (DF), Bruker, USA). Methyl heptadecanoate (C17:0) was used as internal standard. The separation of FAME was achieved using a temperature gradient from $40{ }^{\circ} \mathrm{C}$ to $150{ }^{\circ} \mathrm{C}$ $\left(30{ }^{\circ} \mathrm{C} \mathrm{min}{ }^{-1}\right)$ and from $150{ }^{\circ} \mathrm{C}$ to $250{ }^{\circ} \mathrm{C}\left(5^{\circ} \mathrm{C} \mathrm{min}{ }^{-1}\right)$. The injector and detector temperatures were $250{ }^{\circ} \mathrm{C}$ and $280^{\circ} \mathrm{C}$, respectively, and helium was used as carrier gas.

Extracellular lipase activity was measured in the culture supernatant by a spectrophotometric method using $0.42 \mathrm{mM}$-nitrophenyl butyrate (dissolved in $50 \mathrm{mM}$ phosphate buffer $\mathrm{pH} 7.3$ and acetone $4 \%$, $\mathrm{v} / \mathrm{v})$ as substrate. The reaction mixture $(2.4 \mathrm{~mL}$ of substrate and $0.1 \mathrm{~mL}$ of supernatant sample) was incubated for $15 \mathrm{~min}$ at $37{ }^{\circ} \mathrm{C}$ and it is stopped by placing the tubes in the ice. The absorbances were measured at $410 \mathrm{~nm}$ in a microplate reader (TECAN Sunrise, Switzerland). One unit of activity was defined as the amount of enzyme that produces $1 \mu \mathrm{mol}$ of $p$-nitrophenol per minute under assay conditions.

Citric acid concentration was quantified by high-performance liquid chromatography using an Aminex HPX-87H column (Bio-Rad, USA) coupled to an UV detector (Jasco UV-2075 plus, USA). The mobile phase was $\mathrm{H}_{2} \mathrm{SO}_{4} 5 \mathrm{mM}$ at $0.7 \mathrm{~mL} \mathrm{~min}^{-1}$ and the column temperature was $60^{\circ} \mathrm{C}$, maintained with a column thermostat (Eldex $\mathrm{CH}-150$, USA).

\section{Results and discussion}

\subsection{Microbial lipids accumulation}

In the literature, carbon source, limiting nutrients (especially nitrogen and magnesium) and $\mathrm{pH}$ are often cited as factors that can affect microbial lipids production (Bellou et al., 2016b; Donot et al., 2014). Arabic gum, used as emulsifier, could increase the bioavailability of the solid waste fat to the yeast cells. Moreover, as Y. lipolytica is strictly aerobic, the amount of oxygen available in the medium is a factor with an important impact on yeast growth and microbial lipids production. Thus, the effect of $\mathrm{pH}$, lard concentration, arabic gum concentration and OTR on microbial lipids production by $Y$. lipolytica W29 was studied by applying a Taguchi experimental design (Table 1) and the results obtained at the end of $120 \mathrm{~h}$ of incubation are depicted in Table 2.

From the response obtained for all the experiments it is clear that microbial lipids production was dependent on the combination of the various factors studied. The microbial lipids content accumulated by $Y$. lipolytica W29 cells ranged from $26 \%$ to $58 \%$ (mass of lipids per cell dry weight). In general, oleaginous yeasts have the ability to accumulate microbial oils at more than $20 \%$ of their cell dry weight in intracellular lipids. Particularly for experiments 4 and 8, the content of microbial lipids was higher than $50 \%$, demonstrating the potential of this strain as
Table 2

Microbial lipids content $(\%, \mathrm{w} / \mathrm{w})$, final cell density $\left(\mathrm{g} \mathrm{L}^{-1}\right)$ and fatty acid composition obtained in the experiments designed using Taguchi L9 orthogonal array. Data are average \pm standard deviation of two independent replicates.

\begin{tabular}{|c|c|c|c|c|c|c|}
\hline \multirow[b]{2}{*}{ Experiment } & \multirow[b]{2}{*}{$\%$ Lipids (w/w) } & \multirow[b]{2}{*}{$\begin{array}{l}\text { Cell density } \\
\left(\mathrm{g} \mathrm{L}^{-1}\right)\end{array}$} & \multicolumn{4}{|c|}{ Long Chain Fatty Acids (\%) } \\
\hline & & & Palmitic & Stearic & Oleic & Linoleic \\
\hline 1 & $39.3 \pm 3.1$ & $5.3 \pm 0.1$ & 34.9 & 11.9 & 43.3 & 9.9 \\
\hline 2 & $47.0 \pm 4.0$ & $3.7 \pm 0.1$ & 48.4 & 6.4 & 42.3 & 2.8 \\
\hline 3 & $46.8 \pm 8.9$ & $8.2 \pm 0.2$ & 31.8 & 2.7 & 46.4 & 19.0 \\
\hline 4 & $51.2 \pm 0.4$ & $6.3 \pm 0.2$ & 35.2 & 14.7 & 38.4 & 11.7 \\
\hline 5 & $30.0 \pm 2.1$ & $6.5 \pm 0.3$ & 25.2 & 2.9 & 53.2 & 18.7 \\
\hline 6 & $41.3 \pm 2.1$ & $3.8 \pm 0.1$ & 48.0 & 5.3 & 42.8 & 3.9 \\
\hline 7 & $34.8 \pm 2.9$ & $7.4 \pm 0.3$ & 35.3 & 21.0 & 34.7 & 9.1 \\
\hline 8 & $57.9 \pm 4.1$ & $8.6 \pm 0.2$ & 25.2 & 2.3 & 50.8 & 21.6 \\
\hline 9 & $26.4 \pm 3.0$ & $5.4 \pm 0.2$ & 30.5 & 1.9 & 50.8 & 16.7 \\
\hline Pork lard & - & - & 28.2 & 13.1 & 40.3 & 19.1 \\
\hline
\end{tabular}

an oleaginous microorganism and the possibility to be used for industrial production of microbial oils from pork lard. Also the lipid production (mass of intracellular oil per volume of culture medium) varied between the experiments, ranging from $1.4 \mathrm{~g} \mathrm{~L}^{-1}$ (experiment 9) and $5 \mathrm{~g} \mathrm{~L}^{-1}$ (experiment 8). The maximum lipid production obtained is comparable with others found in the literature for lipids synthesis by $Y$. lipolytica strains from stearin (Papanikolaou et al., 2002) or commercial refined olive oil (Bellou et al., 2016b), and higher than that obtained with pure olive oil (Najjar et al., 2011) or mutton fat (Xiong et al., 2015). Higher production of microbial lipids by this oleaginous yeast $\left(11 \mathrm{~g} \mathrm{~L}^{-1}-16 \mathrm{~g} \mathrm{~L}^{-1}\right.$ ) was found by Saygün et al. (2014) for cells growing in several oil sources. Although the content of lipids was similar to that obtained in the present work $(32 \%-62 \%)$, great amounts of biomass were obtained $\left(14 \mathrm{~g} \mathrm{~L}^{-1}-27 \mathrm{~g} \mathrm{~L}^{-1}\right)$, which justifies such a large concentration of microbial lipids. Other microbial species, such as Aspergillus sp. (Papanikolaou et al., 2011) Rhizopus sp. (Čertik et al., 1997), Emericella nidulans (Roux-Van der Merwe et al., 2005) and Geotrichum sp. (Kinoshita and Ota, 2001) were also reported as high lipid producer from fatty substrates.

When hydrophobic substrates (e.g. fats, oils) are used as carbon source for microbial growth, the accumulation of intracellular lipids (ex novo lipids synthesis) is a growth coupled mechanism, and the fatty acid composition of these microbial lipids are regulated by: (a) the specific incorporation rate of substrate aliphatic chains and (b) the enzymatic batteries that define the intracellular changes of the incorporated fatty acids (Papanikolaou and Aggelis, 2010). In the present work, where pork lard (animal fat) was used as sole carbon and energy source, oleic (35\%-53\%) and palmitic (25\%-48\%) acids were the fatty acids predominantly accumulated by $Y$. lipolytica W29 cells. The content of linoleic $(3 \%-22 \%)$ and stearic $(2 \%-21 \%)$ acids was smaller than the other fatty acids mentioned above. In almost experiments, the yeast showed the capacity to increase its cellular palmitic and oleic acids levels comparatively to the pork lard. It should be stressed out that the lower percentages of oleic acid were obtained in the experiments where stearic acid reached highest proportion (experiments which have in common the lard concentration, $20 \mathrm{~g} \mathrm{~L}^{-1}$ ). The maximum percentages of palmitic acid, for example, were attained in the experiments with the maximum value of OTR (experiments 2, 6 and 7). These results show that the manipulation of culture conditions could be used as a strategy to produce "tailor-made" lipids. As expected for ex novo lipid synthesis, the long chain fatty acids (LCFA) accumulated by Y. lipolytica W29 are the same as those in the pork lard, however the percentage of each LCFA and saturated (27\%-56\%) and unsaturated (44\%-73\%) fractions differ from the initial substrate.

A bio-modification of fatty acid composition of initial lipidic substrate by $Y$. lipolytica was observed and specific lipids with a different composition from pork lard were produced, depending on culture 

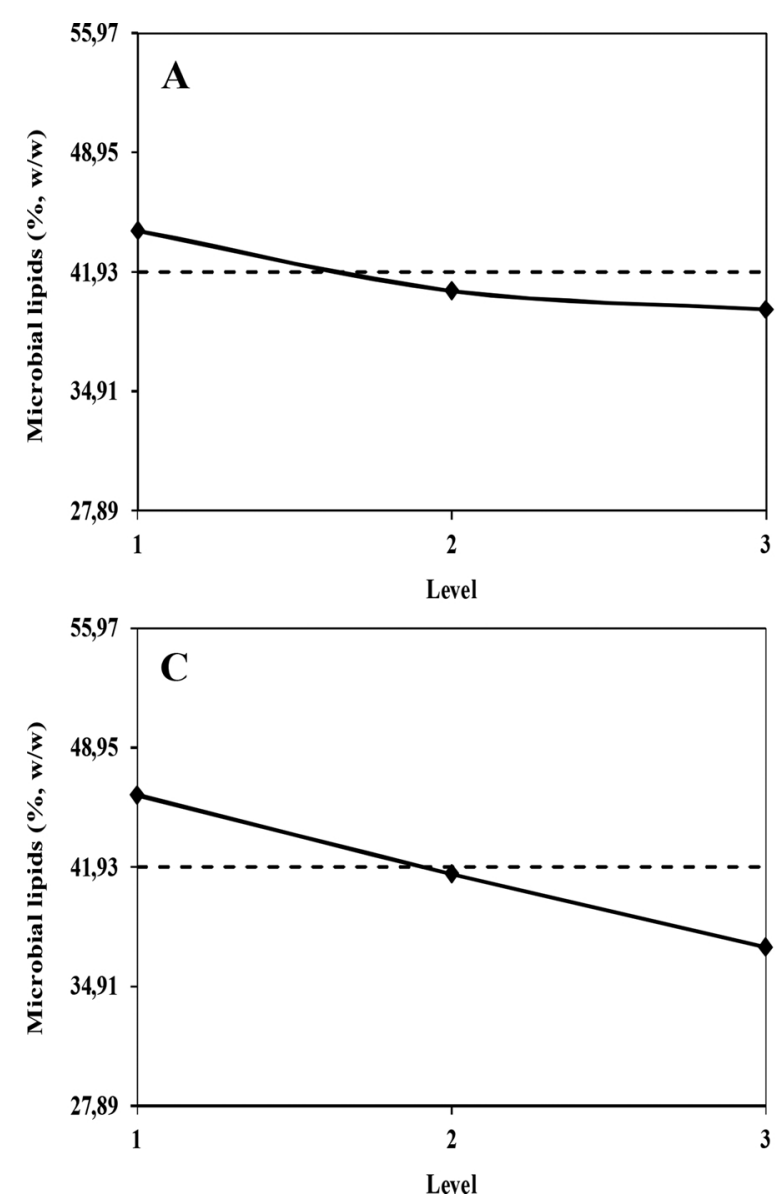
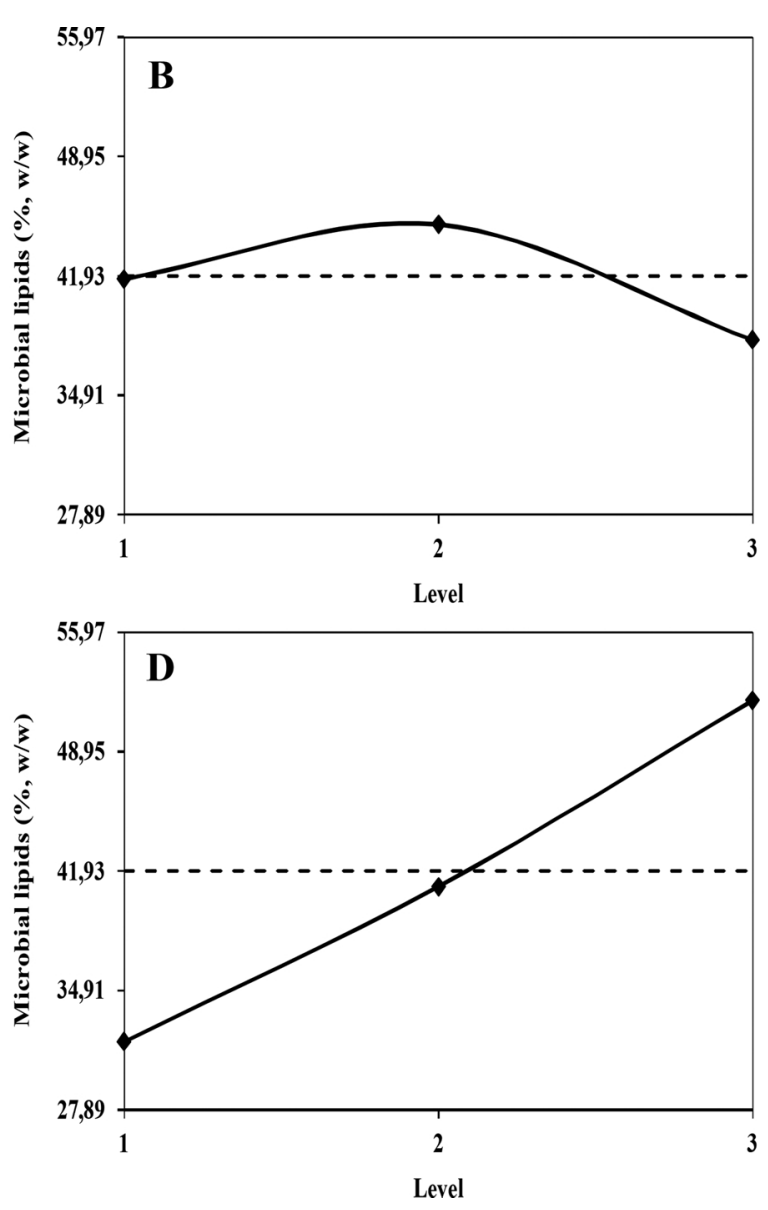

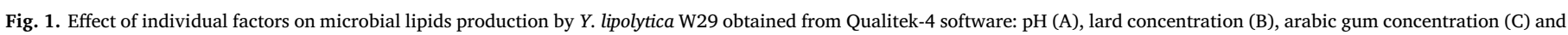

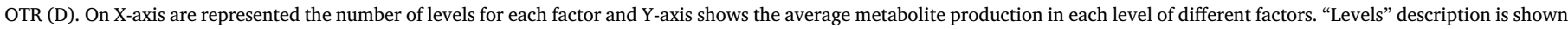
in Table 1.

conditions: (a) lipids with large amounts of palmitic and oleic acids, in which the saturated and unsaturated fraction is similar (experiments 2 and 6); (b) lipids much more unsaturated (73\%) than pork lard (59\%) (experiment 8) and (c) lipids much more saturated (56\%) than pork lard (41\%) (experiment 7). Particularly in this case, lipids are composed by high percentages of palmitic (35\%), stearic (21\%) and oleic (35\%) acids and low amount of linoleic acid (9\%), showing composition similarities to cocoa-butter (which average fatty acid profile is palmitic $23 \%-30 \%$, stearic $32 \%-39 \%$, oleic $30 \%-37 \%$ and linoleic $2-4 \%$ acids) (Papanikolaou and Aggelis, 2010). Although the synthesis of cocoabutter equivalent by $Y$. lipolytica strains from industrial fats (Papanikolaou et al., 2001, 2007) and mixtures of mutton fat and methyl stearate (Xiong et al., 2015) was already reported, this is the first time that is described the bioconversion of pork lard into cocoa-butterlike microbial lipids. In other cases, it has been reported that different Yarrowia lipolytica strains cultivated on blends of fatty acids, spontaneously increased their cellular level of the fatty acid C18:0 (stearic acid), irrespective of the fatty acid composition of the blend employed as substrate (Papanikolaou and Aggelis, 2003, 2010). Due to the ability of $Y$. lipolytica to selectively remove several fatty acids from the fatty materials and accumulate others (Papanikolaou and Aggelis, 2003), diverse lipid-reach wastes (such as those from slaughterhouses and meat processing industry) could be used as substrate for the production of custom-made lipids by this yeast.

Several authors have demonstrated that the composition of low value fatty substrates can be improved by its bio-modification by oleaginous microorganisms, and specialty lipids with high added value can be obtained. Lipids accumulated by $Y$. lipolytica cells growing on different oils and oil industry residues were predominantly composed by oleic acid, independently of oil source and even when this fatty acid was present in small amount in the initial substrate (Saygün et al., 2014). When mutton fat is employed as sole substrate, the cellular lipids of $Y$. lipolytica has a much higher content of oleic acid and lower percentage of stearic acid than the fat substrate. However, the addition of methyl stearate as co-substrate led to the accumulation of lipids more saturated and higher stearic acid amounts was detected (Xiong et al., 2015). It was proved that strains of Candida spp., Langermania sp. and Rhodotorula sp. can accumulate less unsaturated lipids than the initial substrate (polyunsaturated oil), which might be interesting for the production of animal or vegetable fat substitutes with low $\alpha$-linolenic acid content (Aggelis et al., 1997). Exogenous eicosapentaenoic (EPA) and docosahexaenoic (DHA) acids were successfully produced by Geotrichum sp. strains from crude fish oil (Guo et al., 1999) and refined sardine oil (Kinoshita and Ota, 2001), suggesting that the biomass rich in DHA is suitable for feed. Cells of Aspergillus sp. growing on waste cooking olive oil accumulated intracellular lipids more saturated than the initial substrate and enriched with arachidic acid (Papanikolaou et al., 2011).

The effects of each factor at three different levels on microbial lipids production by Y. lipolytica W29 from pork lard are shown in Fig. 1 (left column). The maximum value in each chart identifies the optimum level of that particular factor on the metabolites production. A decrease in microbial lipids content was attained varying the $\mathrm{pH}$ and arabic gum concentration from level 1 (5.6 and $5 \mathrm{~g} \mathrm{~L}^{-1}$, respectively) to level 3 (7.2 and $20 \mathrm{~g} \mathrm{~L}^{-1}$, respectively). Regarding lard concentration, the highest microbial oil content was obtained in the intermediate level $\left(50 \mathrm{~g} \mathrm{~L}^{-1}\right)$ and the raise of OTR from $96 \mathrm{mg} \mathrm{L}^{-1} \mathrm{~h}^{-1}$ to $192 \mathrm{mg} \mathrm{L}^{-1} \mathrm{~h}^{-1}$ (by increasing the agitation rate to $220 \mathrm{rpm}$ ) led to a 1.6-fold improvement in 
Table 3

Analysis of variance (ANOVA) of Taguchi L9 orthogonal array for microbial lipids production by $Y$. lipolytica W29 cultures.

\begin{tabular}{lllll}
\hline & Factors & Variance & F-ratio & Percentage (\%) \\
\hline \multirow{2}{*}{ Microbial lipids } & pH & 35.1 & 2.1 & 2.1 \\
& lard concentration & 69.1 & 4.2 & 5.8 \\
& arabic gum concentration & 119.9 & 7.3 & 11.5 \\
& OTR & 604.7 & 36.9 & 65.2 \\
& Error & 16.4 & - & 15.4 \\
\hline
\end{tabular}

lipids content.

The contribution of each factor in microbial lipids production, statistically analyzed using analysis of variance (ANOVA) allowed differentiation of the most significant process factors (F-ratio $>9$, confidence level of $90 \%$ ) from those with less significance (Table 3). The contribution of each factor is given by $\mathrm{P}(\%)$ and a higher percentage indicates the factor with more impact on the process. It is observed that OTR was by far the most influential factor, with $65.2 \%$ contribution toward variation in microbial lipids production and $\mathrm{pH}$, lard and arabic gum concentration were found as having a negligible influence in the range of the present investigation.

The ANOVA analysis shows that OTR is, undoubted, the most important factor affecting lipid production by $Y$. lipolytica W29 from pork lard. Increasing the OTR value from $96 \mathrm{mg} \mathrm{L}^{-1} \mathrm{~h}^{-1}$ to $192 \mathrm{mg} \mathrm{L}^{-1} \mathrm{~h}^{-1}$ clearly enhanced lipid accumulation by yeast, but a further increase to $480 \mathrm{mg} \mathrm{L}^{-1} \mathrm{~h}^{-1}$ had a slight negative effect on microbial lipids production. In fact, the highest lipid production was obtained in experiments 3,4 and 8 , which have in common the OTR value of $192 \mathrm{mg} \mathrm{L}^{-1} \mathrm{~h}^{-1}$. Although several authors recognized the importance of oxygen on lipid biosynthesis, its effect is not consensual. Rakicka et al. (2015) suggest that an oxygen limitation could lead to an inhibition in carbon metabolism, resulting in citric acid secretion instead of lipids accumulation. Moreover, it was reported that the increase of dissolved oxygen concentration led to higher activity of ATP-citrate lyase and malic enzyme, which are implicated in lipid biosynthesis, resulting in an upregulation of lipid metabolism (Bellou et al., 2014). By contrast, other authors recognize that during the anabolic fatty acid biosynthesis pathways, high dissolved oxygen concentration drives the microbial metabolism toward the synthesis of lipid-free biomass alternatively to the accumulation of lipids. Bati et al. (1984) stated that a high oxygen concentration is necessary in Candida lipolytica growth phase, but in the lipogenesis phase the accumulation of lipids increases when dissolved oxygen concentration is reduced to nearly zero. Also Papanikolaou et al. (2002) reported that in highly aerated Y. lipolytica cultures (oxygen saturation 60\%-70\%) the lipids synthesis is insignificant comparatively to the experiments carried out at an oxygen saturation of 5\%-15\%. Papanikolaou et al. (2007) observed that in experiments with higher aeration and agitation conditions (which correspond to higher oxygen concentration in the medium), remarkable amounts of biomass were obtained, while significantly lower quantities of microbial lipids were accumulated. From the results obtained herein and the works reported in the literature, it seems that oxygen effect is dependent on operational conditions (namely the system and scale used) as well on the type of carbon source, and an adequate balance between oxygen demand for growth and oil accumulation is required. Generally, fatty substrates require the addition of emulsifying agents to allow the fat dispersion into the culture medium and improve the substrate availability for the cells. In this work, arabic gum concentration had no significant effect on microbial lipids production by $Y$. lipolytica W29 cells. Keep the amount of arabic gum in a minimum level in the case of microbial lipids production represents an advantage since the use of emulsifying agents during an industrial bioprocess increases the production costs.

In the present study, substrate (pork lard) concentration had no significant effect on microbial lipids production. It has been reported
Table 4

Optimum culture conditions and expected values predicted by Taguchi method for maximization of microbial lipids production by Y. lipolytica W29 from pork lard.

\begin{tabular}{ll}
\hline Optimized level & Microbial lipids \\
\hline $\mathrm{pH}$ & 5.6 \\
lard concentration $\left(\mathrm{g} \mathrm{L}^{-1}\right)$ & 50 \\
arabic gum concentration $\left(\mathrm{g} \mathrm{L}^{-1}\right)$ & 5 \\
OTR $\left(\mathrm{mg} \mathrm{L}^{-1} \mathrm{~h}^{-1}\right)$ & 192 \\
Expected value & $62.5(\%, \mathrm{w} / \mathrm{w})$ \\
\hline
\end{tabular}

that in ex novo lipid accumulation process (as occurs in hydrophobic substrates), the carbon/nitrogen $(\mathrm{C} / \mathrm{N})$ ratio is not a limiting parameter and microbial oils production is independent of $\mathrm{C} / \mathrm{N}$ ratio level (Donot et al., 2014; Papanikolaou and Aggelis, 2011; Papanikolaou et al., 2002). In this work, different lard concentrations were tested, maintaining the same yeast extract concentration in the medium, which resulted in different $\mathrm{C} / \mathrm{N}$ ratios. Our results are in accordance with the literature, since the lard concentration (and consequently $\mathrm{C} / \mathrm{N}$ ratio) was not a significant factor for lipids synthesis by pork lard in the conditions tested herein.

Taking into account the experimental data from Table 2, Qualitek-4 software established the optimum level of each parameter for microbial lipids production by $Y$. lipolytica W29 from pork lard, as well the maximum theoretical value in these conditions (Table 4). The optimal conditions predicted for microbial lipids and lipase production are similar to the conditions of experiments 8 and 4 (Table 1), respectively, except for the value of $\mathrm{pH}$, but this factor has no significant effect on this bioprocess.

In order to prove the effectiveness of the experimental design and confirm the theoretical value, a confirmation test with three replicates was carried out under the optimum conditions. The average value of lipids content $(58.2 \% \pm 2.7 \%)$ was close to the predicted value and the variation could be attributed to the influence of extraneous variables. In the optimal conditions for microbial oils accumulation, a lipid production of $5 \mathrm{~g} \mathrm{~L}^{-1}$ was obtained and the fatty acids profile (palmitic acid $24 \%$, stearic acid $2 \%$, oleic acid 52\% and linoleic acid 22\%) revealed that unsaturated fraction (74\%) largely exceeded the saturated (26\%) one. This composition makes these lipids a potential source to food supplements, once unsaturated lipids are usually associated to benefits for human health.

\subsection{Lipase and citric acid production}

Besides intracellular lipids accumulation, a simultaneous production of extracellular compounds by Y. lipolytica W29, such as citric acid and lipase (described for the first time from pork lard), was observed (Table 5). Citric acid concentration ranged from $1.1 \mathrm{~g} \mathrm{~L}^{-1}$ (experiment 1) and $9.2 \mathrm{~g} \mathrm{~L}^{-1}$ (experiment 7). The highest citric acid amounts were obtained in the experiments 6 and 7 (which had in common the value of

Table 5

Maximum lipase activity and citric acid production obtained in the experiments designed using Taguchi L9 orthogonal array. Data are average \pm standard deviation of two independent replicates.

\begin{tabular}{lll}
\hline Experiment & Maximum lipase activity $\left(\mathrm{UL}^{-1}\right)$ & Citric acid $\left(\mathrm{g} \mathrm{L}^{-1}\right)$ \\
\hline 1 & $309 \pm 21$ & $1.1 \pm 0.6$ \\
2 & $224 \pm 60$ & $5.9 \pm 1.1$ \\
3 & $490 \pm 27$ & $4.8 \pm 0.5$ \\
4 & $560 \pm 23$ & $4.1 \pm 0.2$ \\
5 & $85 \pm 18$ & $4.8 \pm 0.1$ \\
6 & $154 \pm 27$ & $7.8 \pm 2.1$ \\
7 & $201 \pm 1$ & $9.2 \pm 0.9$ \\
8 & $402 \pm 50$ & $6.0 \pm 0.7$ \\
9 & $133 \pm 76$ & $6.3 \pm 0.4$ \\
\hline
\end{tabular}



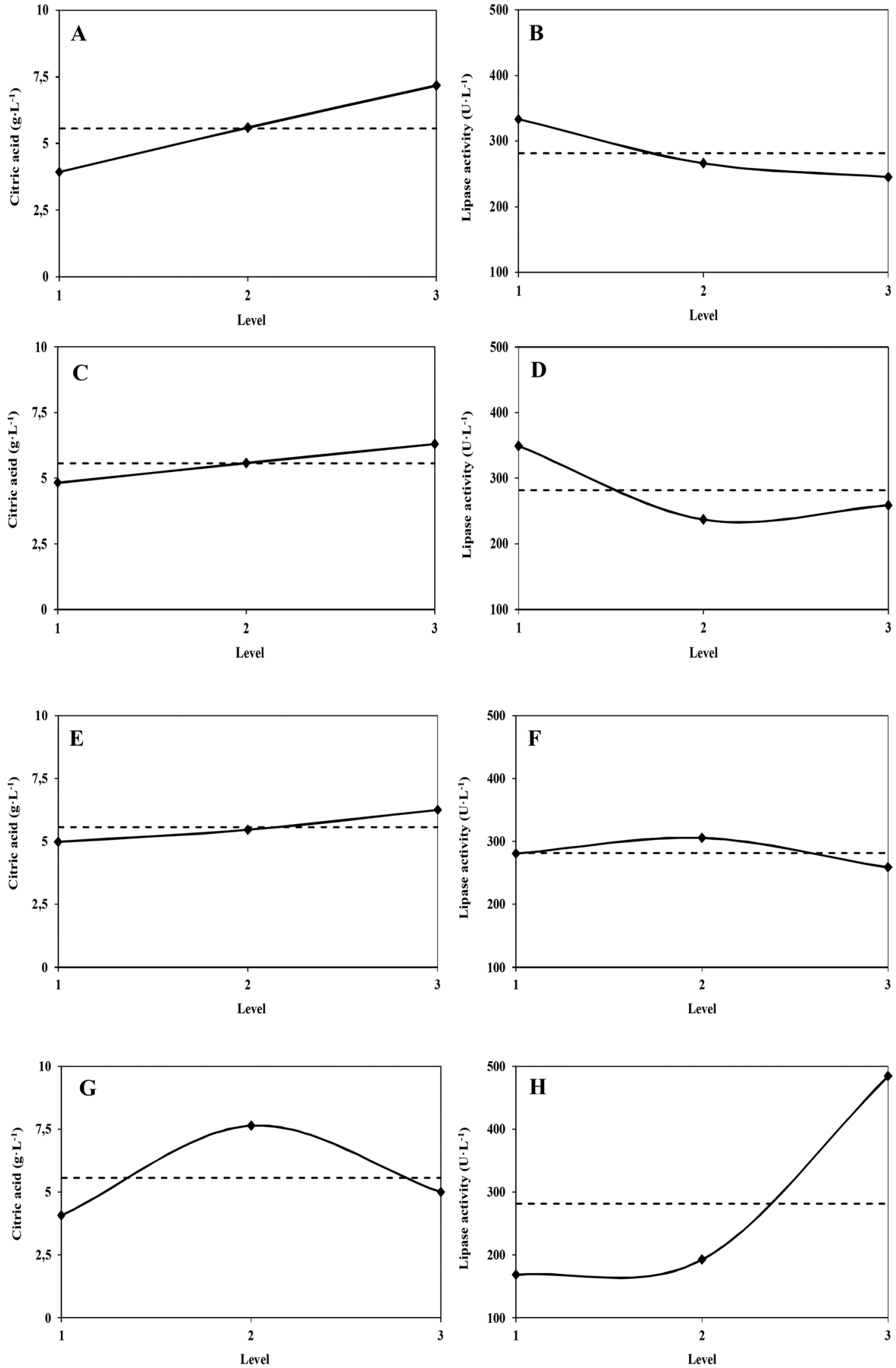

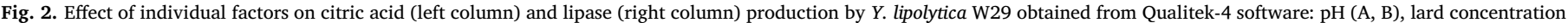

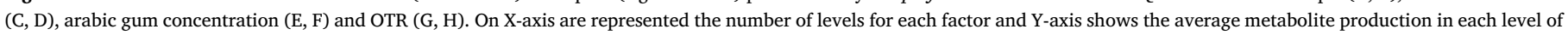
different factors. "Levels" description is shown in Table 1. 
OTR of $480 \mathrm{mg} \mathrm{L}^{-1} \mathrm{~h}^{-1}$ ), followed by values obtained in the experiments 8 and 9 (all at initial $\mathrm{pH}$ of 7.2). Lipase production was also dependent on the combination of the various factors studied and ranged from $85 \mathrm{UL}^{-1}$ (experiment 5) and $560 \mathrm{U} \mathrm{L}^{-1}$ (experiment 4). The highest production was obtained in experiments 3,4 and 8 , which had in common the same value of OTR $\left(192 \mathrm{mg} \mathrm{L}^{-1} \mathrm{~h}^{-1}\right)$.

The effects of each factor on citric acid and lipase production by $Y$. lipolytica W29 from pork lard are shown in Fig. 2. A decrease in lipase activity was attained varying the $\mathrm{pH}$ from 5.6 (level 1) to 7.2 (level 3). However, a significant improvement on citric acid production was obtained by increasing $\mathrm{pH}$ from 5.6 to 7.2. Lard concentration had distinct effects depending on the response of interest. While the maximum citric acid concentration was obtained in level $3\left(80 \mathrm{~g} \mathrm{~L}^{-1}\right)$, lipase production was maximal in level $1\left(20 \mathrm{~g} \mathrm{~L}^{-1}\right)$. Regarding arabic gum, as its concentration increased from level 1 to level 3 (from $5 \mathrm{~g} \mathrm{~L}^{-1}$ to $20 \mathrm{~g} \mathrm{~L}^{-1}$ ) the citric acid production slightly increased, while the maximum lipase induction was obtained in the intermediate level. The raise of OTR from $96 \mathrm{mg} \mathrm{L}^{-1} \mathrm{~h}^{-1}$ to $192 \mathrm{mg} \mathrm{L}^{-1} \mathrm{~h}^{-1}$ led to a 2.4 -fold improvement in lipase average production, but citric acid production was favored by the highest value of OTR ( $\left.480 \mathrm{mg} \mathrm{L}^{-1} \mathrm{~h}^{-1}\right)$.

The analysis of variance (Table 6) reveals that for lipase production, OTR was by far the most influential factor (79.4\%), followed by lard concentration $(8.4 \%)$. Arabic gum concentration and $\mathrm{pH}$ were found as having a negligible influence on the production of lipase by $Y$. lipolytica cells from pork lard in the range of the present investigation. In lipase producing cultures, which commonly occurred in water-immiscible substrates such as oils and fatty acids, oxygen availability is a crucial parameter because fatty substrates coat the gas-liquid interface with a layer of oil, reducing the oxygen mass transfer (Salehmin et al., 2013). Several reports have shown that the increase of dissolved oxygen until certain levels led to an improvement of lipase induction from fatty substrates (Alonso et al., 2005; Lopes et al., 2008, 2009). In this work, the increase of OTR from $96 \mathrm{mg} \mathrm{L}^{-1} \mathrm{~h}^{-1}$ to $192 \mathrm{mg} \mathrm{L}^{-1} \mathrm{~h}^{-1}$ resulted in the highest values of lipase activity, but the further increase to $480 \mathrm{mg} \mathrm{L}^{-1} \mathrm{~h}^{-1}$ had a negative effect. This was probably due to a possible oxidative stress imposed to the cells by high dissolved oxygen concentrations. Although in this work the influence of lard concentration has been small, Kamzolova et al. (2005) observed that the concentration of rapeseed oil was the essential parameter for lipase production by $Y$. lipolytica strains, which indicates that the effect of carbon source concentration depends on the nature of fatty substrate.

OTR (43\%) and $\mathrm{pH}(33 \%)$ were the most influential factors affecting citric acid production by $Y$. lipolytica W29 from lard. The highest citric acid concentrations were obtained in experiments carried out at $\mathrm{pH}$ of 7.2 or at an OTR equal to $480 \mathrm{mg} \mathrm{L}^{-1} \mathrm{~h}^{-1}$. Ferreira et al. (2016) also concluded that OTR and $\mathrm{pH}$ were the major factors affecting citric acid production by $Y$. lipolytica W29 from glycerol. Normally, the production of great amounts of citric acid is associated with the activity of the enzymes involved in tricarboxylic acid cycle and glyoxylate cycle,

Table 6

Analysis of variance (ANOVA) of Taguchi L9 orthogonal array for lipase and citric acid production by $Y$. lipolytica W29 cultures.

\begin{tabular}{lllll}
\hline & Factors & Variance & F-ratio & Percentage (\%) \\
\hline \multirow{2}{*}{ Lipase } & pH & 12710.6 & 6.8 & 4.7 \\
& lard concentration & 21178.9 & 11.3 & 8.4 \\
& arabic gum concentration & 3291.2 & 1.8 & 0.6 \\
& OTR & 184874.1 & 98.5 & 79.4 \\
& Error & 1877.4 & - & 6.9 \\
Citric acid & pH & 15.8 & 19.1 & 32.7 \\
& lard concentration & 3.3 & 4.9 & 5.3 \\
& arabic gum concentration & 2.5 & 3.3 & 3.6 \\
& OTR & 24.8 & 39.4 & 43 \\
& Error & 0.8 & - & 15.3 \\
\hline
\end{tabular}

Table 7

Optimum culture conditions and expected values predicted by Taguchi method for maximization of lipase $\left(\mathrm{U} \mathrm{L}^{-1}\right)$ and citric acid $\left(\mathrm{g} \mathrm{L}^{-1}\right)$ production by $Y$. lipolytica W29 from pork lard.

\begin{tabular}{lll}
\hline Optimized level & Lipase & Citric acid \\
\hline $\mathrm{pH}$ & 5.6 & 7.2 \\
lard concentration $\left(\mathrm{g} \mathrm{L}^{-1}\right)$ & 20 & 80 \\
arabic gum concentration $\left(\mathrm{g} \mathrm{L}^{-1}\right)$ & 10 & 20 \\
OTR $\left(\mathrm{mg} \mathrm{L}^{-1} \mathrm{~h}^{-1}\right)$ & 192 & 480 \\
Expected value & $629.9 \mathrm{U} \mathrm{L}^{-1}$ & $10.7 \mathrm{~g} \mathrm{~L}^{-1}$ \\
\hline
\end{tabular}

which increased under conditions of high oxygen transfer rates (Kamzolova et al., 2003).

In the present study, substrate concentration had no significant effect on citric acid production and the negligible effect of $\mathrm{C} / \mathrm{N}$ ratio is in accordance with some published works with the same yeast strain (Ferreira et al., 2016), although a hydrophilic substrate (glycerol) has been used. However, some studies demonstrated that higher citric acid production was achieved increasing the amount of carbon source (André et al., 2009) and in nitrogen-limited conditions (Levinson et al., 2007).

Optimal conditions for lipase production are similar to those of microbial lipids, particularly $\mathrm{pH}$ and OTR (the factor with more influence for both bioprocesses) while for citric acid production significant differences in operating conditions from those that optimize lipids production were found (Table 7). In fatty environments, the yeast $Y$. lipolytica secretes to the culture medium several extracellular lipases that hydrolyze the oils and fats producing free fatty acids (FFA), which will be incorporated into the cell. In the cytosol, these FFA are activated by fatty acyl-CoA synthetase to produce acyl-CoA, which is converted to triacylglycerols by $D G A 1$ and $D G A 2$ genes and accumulated in a particle called lipid body (Ledesma-Amaro and Nicaud, 2016). Thus, it is not surprising that the optimal conditions for lipids accumulation and lipase production be similar, since a higher lipase secretion will corresponds to an increase of lard hydrolysis and FFA incorporation into the cell.

In optimal conditions for microbial lipids production is more feasible take advantage of simultaneous lipase production. However is possible, at any time, to set operating conditions for maximum citric acid production, with the same technology and equipment. This versatility is in line with the assumptions of biorefinery concept and allows choosing which compounds will be produced according to market demands.

The capacity of a simultaneous production of citric acid (the demands are ever increasing due to the citric acid application as acidulant and anti-oxidant in food and beverage industry, pharmaceutical, etc.) and lipase (catalyze several biotransformation reactions which have wide uses for industrial applications) reduces the production cost of microbial lipids and inserts this bioprocess in the biorefinery concept.

\subsection{Bioreactor experiments}

As OTR was by far the most influential factor on lipids synthesis at 0.5-L flask scale, thus experiments were carried out in a 2-L BIOLAB bioreactor at different values of OTR: (1) $122 \mathrm{mg} \mathrm{L}^{-1} \mathrm{~h}^{-1}$, a value of OTR similar to that optimized by the Taguchi method and (2) $605 \mathrm{mg} \mathrm{L}^{-1} \mathrm{~h}^{-1}$, that corresponds to a 5-fold increase in OTR compared to the value optimized by Taguchi method (Table 8).

Microbial lipids content $(\%, \mathrm{w} / \mathrm{w})$ obtained in bioreactor experiment was analogous to that obtained in Erlenmeyer flask experiment carried out in optimum conditions. However, the amount of lipids per culture medium $\left(\mathrm{g} \mathrm{L}^{-1}\right)$ was higher in bioreactor experiments, due to the improvement on final cellular density, proving that a stirred tank bioreactor is a proper system to increase lipids production. 
Table 8

Values of experimental OTR, microbial lipids content (\%, w/w), cell density $\left(\mathrm{g} \mathrm{L}^{-1}\right)$ and fatty acid composition obtained in bioreactor experiments. Data are average \pm standard deviation of two independent replicates.

\begin{tabular}{lllllll}
\hline OTR & \% Lipids \\
$\left(\mathrm{mg} \mathrm{L}^{-1} \mathrm{~h}^{-1}\right)$ & $\begin{array}{l}\text { Cell density } \\
(\mathrm{w} / \mathrm{w})\end{array}$ & $\left(\mathrm{g} \mathrm{L}^{-1}\right)$ & \multicolumn{2}{l}{ Long chain fatty acids (\%) } & \\
\cline { 4 - 7 } & & & Palmitic & Stearic & Oleic & Linoleic \\
\hline $122 \pm 36$ & $56 \pm 3$ & $11.8 \pm 0.5$ & 22 & 8 & 43 & 27 \\
$605 \pm 38$ & $48 \pm 2$ & $13.1 \pm 0.4$ & 21 & 6 & 48 & 25 \\
\hline
\end{tabular}

No improvement in lipids content was attained with the increase of OTR value and an OTR equal to $122 \mathrm{mg} \mathrm{L}^{-1} \mathrm{~h}^{-1}$ (corresponding to $200 \mathrm{rpm}$ and $1 \mathrm{vvm}$ ) was sufficient for the production of microbial lipids. It should be stressed out that the possibility to operate at lower conditions of stirring speed and specific aeration rate represents important savings in costs with power consumption, making this bioprocess economically interesting. The maximum value of lipids content and lipids production $\left(6.6 \mathrm{~g} \mathrm{~L}^{-1}\right)$ obtained in the present work are similar to others found in literature for Y. lipolytica wild strains (Bellou et al., 2016b; Papanikolaou et al., 2003, 2002). Higher cellular lipids concentration was obtained by Saygün et al. (2014), because higher biomass concentration was reached. Taking into account the great content of microbial lipids obtained herein (56\%), the use of high cellular density cultures will be advantageous to obtain higher cellular lipids concentration. Since cellular growth was enhanced by raising OTR, a two stage oxygen strategy could be implemented: in the first stage high OTR value could be used to reach high cell density, and in the second stage low oxygen transfer could be employed to enhance the accumulation of lipids.

Despite some studies indicate that great levels of lipid synthesis were achieved in highly aerated cultures (Bellou et al., 2014; Tai and Stephanopoulos, 2013), other authors have reported that high aeration or stirring rates do not improve the ex novo microbial oils accumulation (Karamerou et al., 2016; Rakicka et al., 2015) and may boost their degradation by increasing the acyl-CoA oxidase activity (Papanikolaou et al., 2007). Bati et al. (1984) observed that dissolved oxygen level nearly to zero favored lipids accumulation by Candida lipolytica. In fact, in this work the dissolved oxygen profiles obtained during the experiments demonstrate that at lower agitation and aeration conditions the dissolved oxygen remained below $35 \%$ almost all the process (Fig. 3). However, in the experiments conducted at higher stirring speed and specific aeration rate the dissolved oxygen never dropped to zero and after $8 \mathrm{~h}$ the concentration stabilized near to $70 \%$. Oxygen profiles

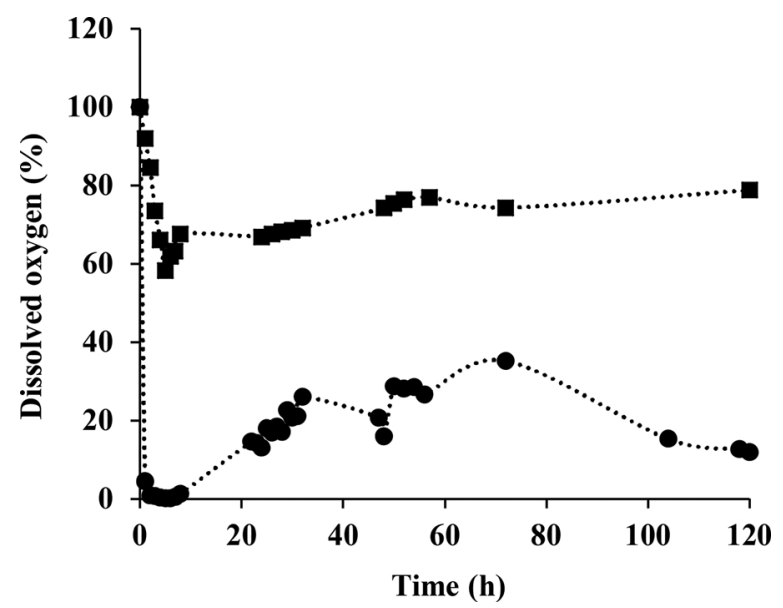

Fig. 3. Dissolved oxygen profiles obtained in Y. lipolytica W29 batch cultures during microbial lipids production in pork lard medium at OTR equal to: $122 \mathrm{mg} \mathrm{L}^{-1} \mathrm{~h}^{-1}$ (๑) and $605 \mathrm{mg} \mathrm{L}^{-1} \mathrm{~h}^{-1}(\square)$.

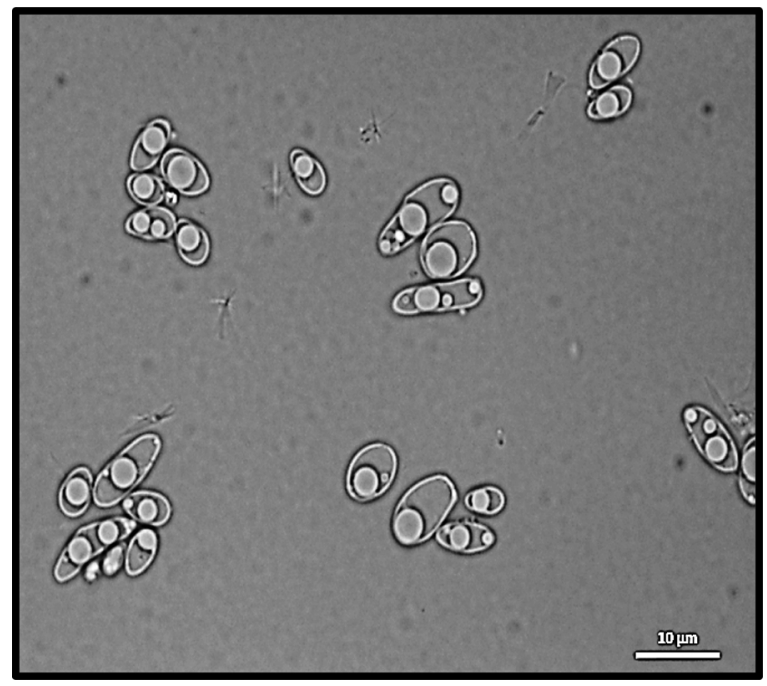

Fig. 4. Light microscopy image of Y. lipolytica W29 cells: visualization of lipid bodies in the cytoplasm during growth in pork lard medium after $120 \mathrm{~h}$.

obtained are in accordance with the fact that oxygen consumption rate decreased during lipogenic phase compared to growth phase (Blazeck et al., 2014). During the first $8 \mathrm{~h}$, corresponding to exponential growth phase, the oxygen concentration dropped to $0 \%$ (at OTR equal to $122 \mathrm{mg} \mathrm{L}^{-1} \mathrm{~h}^{-1}$ ) and $60 \%$ (at OTR equal to $605 \mathrm{mg} \mathrm{L}^{-1} \mathrm{~h}^{-1}$ ), increasing and stabilized after this period.

The composition of fatty acids from lipids accumulated by yeast cells is similar for both experimental conditions in bioreactor and oleic acid was the predominant fatty acid, followed by linoleic and palmitic acids (Table 8). However, in highly aerated conditions the unsaturatedto-saturated fatty acids ratio (2.7) was higher than in low aerated conditions. Comparatively to the initial substrate, an increase of palmitic, oleic and linoleic acids and a decrease of stearic acid were observed in both aeration conditions. As occurred in Erlenmeyer flask experiments, the manipulation of operational conditions in the bioreactor (stirring speed and aeration rate) allows the production of tailormade lipids. The biotransformation of lard into microbial lipids in the conditions tested herein led to the synthesis of less saturated lipids $(27 \%-30 \%)$ than the initial substrate (commercial pork lard used in this work had $41 \%$ of saturated fatty acids). This shows the possibility to convert less unsaturated lipids, such as animal fat, into more unsaturated ones, which can be used for animal feed or food supplements.

The microscopic visualization of $Y$. lipolytica W29 cells growing in pork lard revealed that the fatty substrate and dissolved oxygen concentration did not induced hyphae formation and yeast cells displayed a typical oval form (Fig. 4). Additionally, it was possible to clearly visualize the oil accumulated as lipid bodies in the cytoplasm. Most of the cells had multiple lipid bodies, which occupied more than half of cell volume. The effect of hydrophobic or hydrophilic carbon sources on $Y$. lipolytica dimorphism is controversial, and other factors (e.g. dissolved oxygen and nitrogen source) besides substrate must be taken into account. Bellou et al. (2014) observed that low aeration conditions induced mycelium formation, regardless if hydrophilic (glucose or glycerol) or hydrophobic (olive oil) substrates were used as carbon source. But in highly aerated conditions, Y. lipolytica cultures formed only single cells in all substrates. By contrast, Papanikolaou et al. (2007) reported that a true mycelium was developed on all $Y$. lipolytica cultures growing in stearin (an industrial derivative of tallow), independently of the fat or nitrogen concentration and mode of culture.

As occurred in Erlenmeyer flasks experiments, also in bioreactor the simultaneous production of citric acid and lipase was observed (Fig. 5). While the maximum lipase production was obtained in the exponential phase of growth, citric acid synthesis was enhanced only in the 


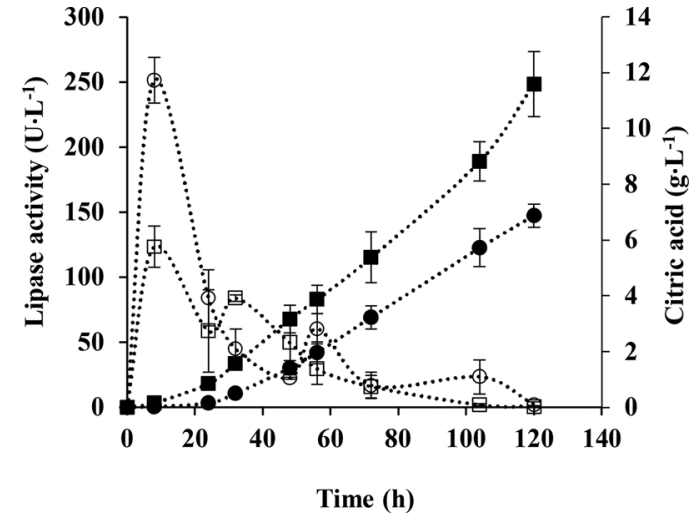

Fig. 5. Citric acid (close symbols) and lipase activity (open symbols) profiles obtained for $Y$. lipolytica W29 batch cultures growing in a lard based medium at OTR equal to: $122 \mathrm{mg} \mathrm{L}^{-1} \mathrm{~h}^{-1}(\bullet, \bigcirc)$ and $605 \mathrm{mg} \mathrm{L}^{-1} \mathrm{~h}^{-1}(\square, \square)$. Data are average \pm standard deviation of two independent replicates.

stationary phase, which is in accordance with previous works regarding the production of these metabolites from fatty substrates (Lopes et al., 2008; Papanikolaou et al., 2008).

The increase of OTR led to an improvement of citric acid production. A 1.7-fold enhancement on citric acid concentration was achieved in the higher aeration condition. This result is in accordance with the optimum conditions predicted by Taguchi method, in which the highest level of OTR ( $480 \mathrm{mg} \mathrm{L}^{-1} \mathrm{~h}^{-1}$ ) is the best condition to achieve the maximum citric acid production. Large productions of citric acid are is usually associated with high dissolved oxygen concentrations in the culture medium (Ferreira et al., 2016) due to the increase of the activity of enzymes involved in tricarboxylic acid and glyoxylate cycles (Kamzolova et al., 2003).

Concerning the lipase production, the profile through the time was similar in both experiments, but 2 -fold improvement in lipase activity was obtained in the experiments carried out with lower OTR value (122 $\mathrm{mg} \mathrm{L}^{-1} \mathrm{~h}^{-1}$ ), which is similar to optimum level predicted by Taguchi method (192 $\mathrm{mg} \mathrm{L}^{-1} \mathrm{~h}^{-1}$ ).

Besides lipids synthesis, the concomitant induction of lipase and citric acid secretion obtained in this bioprocess constitutes a side biotechnological application on its own, thus allowing setting the operating conditions according to market demands of the target compounds within a biorefinery approach.

From an industrial and commercial viewpoint, microbial oils production should fulfil three parameters: (a) high amounts of oil produced; (b) profile of fatty acids; and (c) the ability of microorganisms to utilize low or negative cost raw materials, since the carbon sources normally constitute over $60 \%$ of the total production cost (Béligon et al., 2016; Thevenieau and Nicaud, 2013). The results obtained during this study show that the bioprocess herein described satisfies these requirements, particularly if high cell density cultures are obtained. Additionally, the nutritional value of microbial lipids produced by $Y$. lipolytica W29 was higher than the animal fat used, demonstrating that they could be as a source of food supplements or animal feed.

\section{Conclusions}

According to Taguchi method, OTR value is the major factor affecting microbial lipids production by $Y$. lipolytica W29 from pork lard. In optimal conditions, a lipids content of $58 \%(w / w)$ was reached in batch cultures. It was demonstrated that the composition of yeast oils could be handling by the manipulation of operational and nutritional conditions, obtaining tailor-made lipids.

This study provides valuable knowledge that can be harnessed for future works, particularly for the production of microbial oils, lipase and citric acid by $Y$. lipolytica from lipid-reach wastes, such as effluents of slaughterhouses and meat processing industries. Due to its ability to degrade low cost wastes and produce a diversity of added value metabolites, Y. lipolytica may be explored as biorefinery platform.

\section{Acknowledgements}

This work was financially supported by the Portuguese Foundation for Science and Technology (FCT) under the scope of the project TÜBITAK 2014 (TUBITAK/0009/2014) and of the strategic funding of UID/BIO/04469/2013 unit and COMPETE 2020 (POCI-01-0145FEDER-006684), Post-Doctoral grant (SFRH/BPD/101034/2014) attributed to Marlene Lopes and BioTecNorte operation (NORTE-010145-FEDER-000004) funded by European Regional Development Fund under the scope of Norte2020 - Programa Operacional Regional do Norte.

\section{References}

Abghari, A., Chen, S., 2014. Yarrowia lipolytica as an oleaginous cell factory platform for production of fatty acid-based biofuel and bioproducts. Front. Energy Res. 2 (21), $1-21$.

Aggelis, G., Papadiotis, G., Komaitis, M., 1997. Microbial fatty acid specificity. Folia Microbiol. 42 (2), 117-120.

Alonso, F.O.M., Oliveira, E.B.L., Dellamora-Ortiz, G.M., Pereira-Meirelles, F.V., 2005. Improvement of lipase production at different stirring speeds and oxygen levels. Braz. J. Chem. Eng. 22 (1), 9-18.

André, A., Chatzifragkou, A., Diamantopoulou, P., Sarris, D., Philippoussis, A., GaliotouPanayotou, M., Komaitis, M., Papanikolaou, S., 2009. Biotechnological conversions of bio-diesel-derived crude glycerol by Yarrowia lipolytica strains. Eng. Life Sci. 9, $468-478$.

Béligon, V., Christophe, G., Fontanille, P., Larroche, C., 2016. Microbial lipids as potential source to food supplements. Curr. Opin. Food Sci. 7, 35-42.

Banković-Ilić, I.B., Stojković, I.J., Stamenković, O.S., Veljkovic, V.B., Hung, Y.-T., 2014 Waste animal fats as feedstocks for biodiesel production. Renew. Sustain. Energy Rev. $32,238-254$.

Bati, N., Hammond, E.G., Glatz, B.A., 1984. Biomodification of fats and oils: trials with Candida lipolytica. J. Am. Oil Chem. Soc. 61 (11), 1743-1746.

Bellou, S., Makri, A., Triantaphyllidou, I.-E., Papanikolaou, S., Aggelis, G., 2014. Morphological and metabolic shifts of Yarrowia lipolytica induced by alteration of the dissolved oxygen concentration in the growth environment. Microbiol.-U.K. 160, $807-817$.

Bellou, S., Triantaphyllidou, I.-E., Aggeli, D., Elazzazy, A.M., Baeshen, M.N., Aggelis, G., 2016a. Microbial oils as food additives: recent approaches for improving microbial oil production and its polyunsaturated fatty acid content. Curr. Opin. Biotechnol. 37, 24-35.

Bellou, S., Triantaphyllidou, I.-E., Mizerakis, P., Aggelis, G., 2016b. High lipid accumulation in Yarrowia lipolytica cultivated under double limitation of nitrogen and magnesium. J. Biotechnol. 234, 116-126.

Blazeck, J., Hill, A., Liu, L., Knight, R., Miller, J., Pan, A., Otoupal, P., Alper, H.S., 2014. Harnessing Yarrowia lipolytica lipogenesis to create a platform for lipid and biofuel production. Nat. Commun. 5 (3131), 1-10.

Čertik, M., Baltészová, L., Šajbidor, J., 1997. Lipid formation and $\gamma$-linolenic acid production by Mucorales fungi grown on sunflower oil. Lett. Appl. Microbiol. 25, 101-105.

Cheirsilp, B., Louhasakul, Y., 2013. Industrial wastes as a promising renewable source for production of microbial lipid and direct transesterification of the lipid into biodiesel. Bioresour. Technol. 142, 329-337.

Donot, F., Fontana, A., Baccou, J.C., Strub, C., Schorr-Galindo, S., 2014. Single cell oils (SCOs) from oleaginous yeasts and moulds: production and genetics. Biomass Bioenergy 68, 135-150.

Ferreira, P., Lopes, M., Mota, M., Belo, I., 2016. Oxygen transfer rate and pH as major operating parameters of citric acid production from glycerol by Yarrowia lipolytica W29 and CBS 2073. Chem. Pap. 70 (7), 869-876.

Fickers, P., Benetti, P.H., Waché, Y., Marty, A., Mauersberger, S., Smit, M.S., Nicaud, J.M., 2005. Hydrophobic substrate utilisation by the yeast Yarrowia lipolytica, and its potential application. FEMS Yeast Res. 5, 527-543.

Guo, X., Tomonaga, T., Yanagihara, Y., Ota, Y., 1999. Screening for yeasts incorporating the exogenous eicosapentaenoic and docosahexaenoic acids from crude fish oil. J. Biosci. Bioeng. 87 (2), 184-189.

Kamzolova, S.V., Shishkanova, N.V., Morguniv, I.G., Finogenova, T.V., 2003. Oxygen requirements for growth and citric acid production of Yarrowia lipolytica. FEMS Yeast Res. 3, 217-222.

Kamzolova, S.V., Morgunov, I.G., Aurich, A., Perevoznikova, O.A., Shishkanova, N.V., Stottmeister, U., Finogenova, T.V., 2005. Lipase secretion and citric acid production in Yarrowia lipolytica yeast grown on animal and vegetable fat. Food Technol. Biotechnol. 43 (2), 113-122.

Karamerou, E.E., Theodoropoulos, C., Webb, C., 2016. A biorefinery approach to microbial oil production from glycerol by Rhodotorula glutinis. Biomass Bioenergy 89, $113-122$.

Kinoshita, H., Ota, Y., 2001. Concentration of docosahexaenoic acid from fish oil using 
Geotrichum sp. FO347-2. Biosci. Biotechnol. Biochem. 65 (5), 1022-1026.

Ledesma-Amaro, R., Nicaud, J.-M., 2016. Yarrowia lipolytica as a biotechnological chassis to produce usual and unusual fatty acids. Prog. Lipid Res. 61, 40-50.

Levinson, W.E., Kurtzman, C.P., Kuo, T.M., 2007. Characterization of Yarrowia lipolytica and related species for citric acid production from glycerol. Enzyme Microb. Technol. 41, 292-295.

Lopes, M., Gomes, N., Gonçalves, C., Coelho, M.A.Z., Mota, M., Belo, I., 2008. Yarrowia lipolytica lipase production enhanced by increased air pressure. Lett. Appl. Microbiol. $46,255-260$.

Lopes, M., Gomes, N., Mota, M., Belo, I., 2009. Yarrowia lipolytica growth under increased air pressure: influence on enzymes production. Appl. Biochem. Biotechnol. 159 (1), 46-53.

Lopes, M., Mota, M., Belo, I., 2013. Oxygen mass transfer rate in a pressurized lab-scale stirred bioreactor. Chem. Eng. Technol. 36, 1779-1784.

Najjar, A., Robert, S., Guérin, C., Violet-Asther, M., Carrière, F., 2011. Quantitative study of lipase secretion, extracellular lipolysis, and lipid storage in the yeast Yarrowia lipolytica grown in the presence of olive oil: analogies with lipolysis in humans. Appl. Microbiol. Biotechnol. 89, 1947-1962.

Papanikolaou, S., Aggelis, G., 2003. Selective uptake of fatty acids by the yeast Yarrowia lipolytica. Eur. J. Lipid Sci. Technol. 105, 651-655.

Papanikolaou, S., Aggelis, G., 2010. Yarrowia lipolytica: a model microorganism used for the production of tailor-made lipids. Eur. J. Lipid Sci. Technol. 112, 639-654.

Papanikolaou, S., Aggelis, G., 2011. Lipids of oleaginous yeasts. Part II: technology and potential applications. Eur. J. Lipid Sci. Technol. 113, 1052-1073.

Papanikolaou, S., Chevalot, I., Komaitis, M., Aggelis, G., Marc, I., 2001. Kinetic profile of the cellular lipid composition in an oleaginous Yarrowia lipolytica capable of producing a cocoa-butter substitute from industrial fats. Ant. van Leeuw. 80, 215-224.

Papanikolaou, S., Chevalot, I., Komaitis, M., Marc, I., Aggelis, G., 2002. Single cell oil production by Yarrowia lipolytica growing on an industrial derivative of animal fat in batch cultures. Appl. Microbiol. Biotechnol. 58, 308-312.

Papanikolaou, S., Muniglia, L., Chevalot, I., Aggelis, G., Marc, I., 2003. Accumulation of a cocoa-butter-like lipid by Yarrowia lipolytica cultivated on agro-industrial residues. Curr. Microbiol. 46, 124-130.

Papanikolaou, S., Chevalot, I., Galiotou-Panayotou, M., Komaitis, M., Marc, I., Aggelis, G., 2007. Industrial derivative of tallow: a promising renewable substrate for microbial lipid, single-cell protein and lipase production by Yarrowia lipolytica. Electron. J. Biotechnol. 10, 425-435.
Papanikolaou, S., Galiotou-Panayotou, M., Fakas, S., Komaitis, M., Aggelis, G., 2008. Citric acid production by Yarrowia lipolytica cultivated on olive-mill wastewaterbased media. Bioresour. Technol. 99, 2419-2428.

Papanikolaou, S., Dimou, A., Fakas, S., Diamantopoulou, P., Philippoussis, A., GaliotouPanayotou, M., Aggelis, G., 2011. Biotechnological conversion of waste cooking olive oil into lipid-rich biomass using Aspergillus and Penicillium strains. J. Appl. Microbiol. 110, 1138-1150.

Rakicka, M., Lazar, Z., Dulermo, T., Fickers, P., Nicaud, J.M., 2015. Lipid production by the oleaginous yeast Yarrowia lipolytica using industrial by-products under different culture conditions. Biotechnol. Biofuels 8, 104-113.

Roux-Van der Merwe, M.P., Badenhorst, J., Britz, T.J., 2005. Fungal treatment of an edible-oil-containing industrial effluent. World J. Microbiol. Biotechnol. 21, 947-953.

Salehmin, M.N.I., Annuar, M.S.M., Chisti, Y., 2013. High cell density fed-batch fermentations for lipase production: feeding strategies and oxygen transfer. Bioprocess Biosyst. Eng. 36 (11), 1527-1543.

Saygün, A., Şahin-Yeşilçubuk, N., Aran, N., 2014. Effects of Different Oil Sources and Residues on Biomass and Metabolite Production by Yarrowia lipolytica YB 423-12. J. Am. Oil Chem. Soc. 91, 1521-1530.

Tai, M., Stephanopoulos, G., 2013. Engineering the push and pull of lipid biosynthesis in oleaginous yeast Yarrowia lipolytica for biofuel production. Metab. Eng. 15, 1-9.

Thevenieau, F., Nicaud, J.-M., 2013. Microorganisms as sources of oils. OCL 20 (6), D603.

Tsigie, Y.A., Wang, C.-Y., Truong, C.-T., Jua, Y.-U., 2011. Lipid production from Yarrowia lipolytica Po1g grown in sugarcane bagasse hydrolysate. Bioresour. Technol. 102 (19), 9216-9222.

Xiong, D., Zhang, H., Xie, Y., Tang, N., Berenjian, A., Song, Y., 2015. Conversion of mutton fat to cocoa butter equivalent by increasing the unsaturated fatty acids at the Sn-2 position of triacylglycerol through fermentation by Yarrowia lipolytica. Am. J. Biochem. Biotechnol. 11 (2), 57-65.

Xue, Z., Sharpe, P.L., Hong, S.-P., Yadav, N.S., et al., 2013. Production of omega-3 eicosapentaenoic acid by metabolic engineering of Yarrowia lipolytica. Nat. Biotechnol. 31, 734-740.

Yamsub, A., Kaewchada, A., Jaree, A., 2014. Pork lard conversion to biodiesel using a microchannel reactor. Korean J. Chem. Eng. 31 (12), 2170-2176.

Zhang, B., Chen, H., Li, M., Gu, Z., Song, Y., Ratledge, C., Chen, Y.Q., Zhang, H., Chen, W., 2013. Genetic engineering of Yarrowia lipolytica for enhanced production of trans-10, cis-12 conjugated linoleic acid. Microb. Cell Fact. 12, 1-8. 